\title{
PENENTUAN KADAR ASAM LEMAK BEBAS PADA MINYAK JELANTAH DENGAN PENAMBAHAN ANTIOKSIDAN ALAMI KULIT PISANG RAJA (Musa sapientum)
}

\author{
Debora N Patty ${ }^{1}$, P.M Papilaya ${ }^{2}$, R. L. Karuwal² \\ ${ }^{1}$ Alumi Program Studi Pendidikan Biologi \\ ${ }^{2}$ Staf Pengajar Program Studi Pendidikan Biologi \\ E-mail: patty_debora@yahoo.com
}

\begin{abstract}
Background: Indonesia as one of agrarian countries rich in natural resources and has a variety of plants that have great potential to be utilized as a natural antioxidant, one of which is a banana. In the utilization of bananas is limited to the meat alone while the skin is only used as waste, whereas banana peels have a high value of benefits, it is evident that the banana skin contains high oxygen activity compared to meat.

Method: The method used is Completely Randomized Design (RAL) with factorial pattern consisting of 5 treatments and 3 repetitions. The results were analyzed statistically with Anova test showed sig value. $0.000<0.05$ followed by Tukey test showing very real difference in each treatment.

Results: The results showed that group P (3) was the best treatment group that decreased free fatty acid content in cooking oil with the addition of natural antioxidant of banana peel (Musa sapientum).

Conclusion: The addition of natural antioxidant of banana skin effect in decreasing free fatty acids fatty acid content with average free fatty acid content with $1 \% \mathrm{~b} / \mathrm{b}, 2 \% \mathrm{w} / \mathrm{b}$ and $3 \% \mathrm{~b} /$ b banana peel powder of $0,2928 \%, 0.2733 \%$ and $0.2370 \%$.
\end{abstract}

Keywords: Free Fatty Acid, Natural Antioxidant, Banana King's Skin.

\begin{abstract}
Abstrak
Latar Belakang: Indonesia sebagai salah satu negara agraris yang kaya sumber daya alam dan memiliki beragam tumbuhan yang berpotensi besar untuk dimanfaatkan sebagai antioksidan alami, salah satunya adalah buah pisang. Dalam pemanfaatannya buah pisang terbatas pada dagingnya saja sedangkan kulitnya hanya dijadikan limbah, padahal kulit pisang memiliki nilai manfaat yang tinggi, terbukti bahwa pada kulit pisang mengandung aktivitas oksigen yang tinggi dibandingkan dengan dagingnya.

Metode: Metode yang digunakan adalah Rancangan Acak Lengkap (RAL) dengan pola factorial terdiri dari 5 perlakuan dan 3 kali pengulangan. Hasil penelitian dianalisis secara statistik dengan uji Anova menunjukan nilai sig. $0.000<0.05$ dilanjutkan dengan uji Tukey yang menunjukkan perbedaan yang sangat nyata pada masing-masing perlakuan.

Hasil: Hasil penelitian menunjukkan kelompok $\mathrm{P}(3)$ adalah kelompok perlakuan terbaik yang menurunkan kadar asam lemak bebas pada minyak jelantah dengan penambahan antioksidan alami kulit pisang raja (Musa sapientum).

Kesimpulan: Penambahan antioksidan alami kulit pisang raja berpengaruh dalam penurunan kadar asam lemak bebas minyak jelantah dengan rata-rata kadar asam lemak bebas dengan penambahan bubuk kulit pisang raja $1 \% \mathrm{~b} / \mathrm{b}, 2 \% \mathrm{~b} / \mathrm{b}$ dan $3 \% \mathrm{~b} / \mathrm{b}$ yaitu $0,2928 \%$, $0,2733 \%$ dan $0,2370 \%$.
\end{abstract}

Kata kunci: Asam Lemak Bebas, Antioksidan Alami, Kulit Pisang Raja, Minyak Jelantah. 


\section{PENDAHULUAN}

Minyak goreng merupakan medium penggoreng bahan pangan yang banyak digunakan masyarakat. Kegiatan memasak adalah sebuah kegiatan rutin yang tidak bisa dihindari. Sebagai akibatnya, minyak goreng merupakan bahan yang sangat diperlukan dalam proses penggorengan. Penggunaan minyak goreng secara terus-menerus dapat mengurangi kualitas minyak goreng. Umumnya bekas minyak goreng tersebut disebut sebagai minyak jelantah. Penggunaan minyak jelantah kadang dicampur dengan minyak goreng segar. Masyarakat tidak menyadari bahwa perilaku tersebut justru akan menurunkan kualitas minyak goreng segar (Kadarwati, 2007).

Penggunaan minyak goreng secara berulang dengan suhu yang tinggi akan mengalami perubahan sifat fisikokimia (kerusakan minyak) seperti warna, bau serta meningkatnya bilangan peroksida dan asam lemak bebas (FFA) yang sukar dicerna oleh tubuh. Menurut Ketaren (2005), minyak goreng yang demikian sudah tidak layak untuk dikonsumsi karena dapat menyebabkan penyakit seperti kanker, menyempitnya pembuluh darah dan gatal pada tenggorokan. Hal itu diakibatkan oleh proses oksidasi, polimerisasi dan hidrolisis (Ketaren, 2005).

Asam lemak bebas merupakan karakteristik yang paling umum digunakan sebagai kontrol kualitas minyak karena asam lemak tersebut akan mempengaruhi sifat fisik, kimia, dan stabilitas minyak selama proses penggorengan. Pada saat awal proses penggorengan, asam lemak bebas juga dihasilkan dari proses oksidasi, tetapi pada tahap selanjutnya asam lemak bebas dihasilkan dari proses hidrolisis yang disebabkan oleh keberadaan air

Reaksi oksidasi pada minyak dapat dihambat dengan menggunakan antioksidan. Pada umumnya zat antioksidan yang digunakan adalah antioksidan sintetik yaitu butil hidroksi anilin (BHA), butil hidroksi toluen (BHT). Bahan antioksidan tersebut dapat meracuni dan bersifat karsinogenik sehingga untuk mengatasi hal tersebut digunakan penganti antioksidan sintetik dengan antioksidan alami (Panangan, 2010). Salah satu antioksidan alami yang baik terdapat dalam buah pisang raja (Musa sapientum) namun dalam pemanfaatanya terbatas pada dagingnya saja sedangkan kulitnya hanya dijadikan limbah padahal kulit pisang memiliki nilai manfaat yang tinggi.

Menurut Someya dalam Nuramanah (2012), terbukti bahwa pada kulit pisang mengandung aktivitas oksigen yang tinggi dibandingkan dengan dagingnya. Menurut Atun dkk. (2007), kulit buah pisang raja masak yang berwarna kuning kaya akan senyawa flavonoid, maupun senyawa fenolik yang lainnya. Flavonoid dan senyawa fenolik merupakan senyawa bioaktif yang menunjukkan berbagai aktivitas yang berguna, seperti antioksidan, antidermatosis, kemopreventif, antikanker, maupun antiviral. Oleh karena itu, kulit pisang memiliki potensi yang cukup baik untuk dimanfaatkan sebagai sumber antioksidan pada bahan pangan.

Widiandani dkk. (2009), penambahan kulit pisang Cavendish (Musa cavendishii) mampu mengurangi penurunan kualitas minyak kelapa yang dipanaskan berulang hingga empat kali pemanasan berdasarkan parameter bilangan iod dan kadar asam lemak bebas.

\section{MATERI DAN METODE}

Penelitian ini dilakukan pada bulan November-Desember 2015 dengan lokasi penelitian Laboratorium Kimia Dasar FMIPA Universitas Pattimura. Alat yang digunakan adalah Erlenmeyer, Alat titrasi, Neraca Analitis, Kertas saring, Kamera digital, Buku dan pena sedangkan ahan yang digunakan adalah Minyak jelantah, Kulit pisang raja, BHT, Alkohol 96\%, NaOH, Indikator PP.

Rancangan penelitian ini menggunakan Rancangan Acak Lengkap (RAL) dengan pola faktorial yang terdiri dari 5 perlakuan $P(+), P(-), P 1, P 2, \quad P 3$ dengan 3 kali pengulangan. Prosedur kerja dalam penelitian ini adalah:

a. Pembuatan bubuk kulit pisang raja

Disiapkan kulit pisang raja yang matang yang akan digunakan, kemudian dicuci bersih di air yang mengalir dan dipotong kecil-kecil kemudian dihaluskan menggunakan blender dan dikering anginkan selama kurang lebih 24 jam hingga benar-benar kering lalu dihaluskan menjadi bubuk dibungkus dan disimpan pada wadah yang tertutup (Nurahmana, 2012). 


\section{Penentuan bubuk kulit pisang raja yang digunakan untuk minyak jelantah}

Pembuatan sampel dilakukan sebagai berikut, minyak jelantah sebanyak $100 \mathrm{~g}$ ditambahkan masing-masing $1 \%$ (P1), 2\% (P2), dan 3\% (P3) bubuk kulit pisang raja yang telah disiapkan. Sebagai pembanding dibuat juga $100 \mathrm{~g}$ minyak tanpa penambahan kulit pisang raja $\left(\mathrm{P}_{-}\right)$dan $100 \mathrm{~g}$ minyak jelantah dengan penambahan BHT $0,1 \%(\mathrm{P}+)$ dan direndam selama 30 menit.

\section{Penentuan kadar asam lemak bebas (FFA).}

Ditimbang masing-masing sebesar 1-2 gram sampel dimasukkan kedalam erlenmeyer $250 \mathrm{~mL}$, selanjutnya dilarutkan dalam pelarut etanol $95 \%$ panas sebanyak $50 \mathrm{ml}$, lalu ditambahkan indikator pp sebanyak 5 tetes. Selanjutnya diaduk selama 30 detik lalu dititrasi dengan larutan $\mathrm{NaOH} 0,1 \mathrm{~N}$. Titrasi dihentikan jika warna larutan berubah menjadi merah muda yang bertahan tidak kurang dari 30 detik (Ketaren, 2008).

Data hasil penelitian di uji secara statistik dengan analisis variansi (Anova). Apabila hasil uji Anova menunjukan hasil yang signifikan $\left(\mathrm{H}_{0}\right.$ ditolak) maka dilanjutkan dengan uji post-hock menggunakan uji Tukey dengan tingkat kebermaknaan 0,05.

\section{HASIL DAN PEMBAHASAN}

Kadar asam lemak bebas pada minyak jelantah dengan penambahan antioksidan alami kulit pisang raja (Musa sapientum) diuji menggunakan metode titrasi asam-basa. Adapun hasil rata-rata kadar asam lemak bebas pada minyak jelantah ini, dapat dilihat pada tabel berikut.
Tabel 1. Hasil Rata-Rata Kadar Asam Lemak Bebas pada Minyak Jelantah dengan Penambahan Antioksidan Alami Bubuk Kulit Pisang Raja.

\begin{tabular}{cc}
\hline Perlakuan & Rata-rata (\%) \\
\hline P (-) & 0,3351 \\
P (+) & 0,2467 \\
P1 & 0,2928 \\
P2 & 0,2733 \\
P3 & 0,2370 \\
\hline
\end{tabular}

Tabel diatas menunjukkan bahwa kontrol negatif memiliki kadar asam lemak bebas lebih tinggi dari perlakuan yang lain. Hal ini sesuai pernyataan Sulieman et al., (2001) bahwa kenaikan kadar asam lemak bebas karena pada saat awal penggorengan, kadar air dalam minyak belum terlalu banyak, tetapi pada proses penggorengan selanjutnya kadar air pada minyak semakin bertambah. Keberadaan air pada minyak akan mempercepat proses hidrolisis dari minyak goreng. Semakin lama penggunan minyak untuk menggoreng semakin tinggi pula kandungan asam lemak bebas yang terbentuk. Untuk mencegah tingginya kadar asam lemak bebas yang terbentuk dapat digunakan bahan alami seperti kulit pisang raja (Musa sapientum). Dari hasil penelitian pada tabel diatas dapat dilihat bahwa bubuk kulit pisang raja dengan konsentrasi 3\% b/b memiliki kadar asam lemak bebas sebesar 0,2370\%. Penurunan kadar asam lemak bebas pada minyak jelantah ini disebabkan adanya antioksidan. Senyawa antioksidan alami yang terdapat pada kulit pisang yaitu katekin, gallokatekin, dan epikatekin yang merupakan golongan senyawa flavonoid. Senyawa antioksidan alami ini adalah multifungsional dan dapat beraksi sebagai pereduksi, penangkap radikal bebas, pengkelat logam, dan peredam terbentuknya singlet oksigen. Selain itu, antioksidan alami tidak hanya menghambat reaksi kimia oksidasi yang dapat merusak makromolekul dan dapat menimbulkan berbagai masalah kesehatan, namun juga menambahkan kandungan nutrisi pada minyak goreng (Ayucitra dkk., 2011). 
Tabel 2. Hasil Anova Kadar Asam Lemak Bebas Pada Minyak Jelantah Dengan Penambahan Antioksidan Alami Kulit Pisang Raja.

\begin{tabular}{ccccc}
\hline $\begin{array}{c}\text { Sum of } \\
\text { Squares }\end{array}$ & Df & $\begin{array}{c}\text { Mean } \\
\text { Square }\end{array}$ & F & Sig. \\
\hline .018 & 4 & .005 & 28.293 & .000 \\
.002 & 10 & .000 & .002 & 10 \\
.002 & 10 & .000 & .002 & \\
\hline
\end{tabular}

Hasil analisis data menunjukan bahwa nilai sig. $0.000<0.05$. Hal ini berarti bahwa terdapat pengaruh yang signifikan penambahan kulit pisang raja (Musa sapientum), maka perlu dilanjutkan dengan uji Tukey, untuk menentukan perbedaan setiap perlakuan bubuk kulit pisang raja. Hasil uji Tukey dapat dilihat pada tabel 3.

Tabel 3. Hasil Uji Tukey Kadar Asam Lemak Bebas pada Minyak Jelantah dengan Penambahan Antioksidan Alami Kulit Pisang Raja (Musa sapientum)

\begin{tabular}{ccc}
\hline Perlakuan & $\begin{array}{c}\text { Rerata } \\
(\%)\end{array}$ & Notasi \\
\hline $\mathrm{P}(+)$ & 0,2467 & $\mathrm{a} \mathrm{b}$ \\
$\mathrm{P}(3)$ & 0,2370 & $\mathrm{a}$ \\
$\mathrm{P}(2)$ & 0,2733 & $\mathrm{~b} \mathrm{c}$ \\
$\mathrm{P}(1)$ & 0,2928 & $\mathrm{c}$ \\
$\mathrm{P}(-)$ & 0,3351 & $\mathrm{~d}$ \\
\hline
\end{tabular}

Keterangan :

Perbedaan notasi menunjukan perbedaan yang sangat nyata.

Dari hasil uji Tukey didapatkan bahwa adanya beda yang nyata antara masingmasing perlakuan maupun dengan kontrol ditandai dengan notasi yang berbeda. Dari data hasil diatas memperlihatkan bahwa $\mathrm{P}(3)$ adalah perlakuan terbaik yang menurunkan kadar asam lemak bebas pada minyak jelantah dengan penambahan antioksidan alami kulit pisang raja (Musa sapientum).

\section{KESIMPULAN DAN SARAN}

Dari hasil penelitian dapat disimpulkan bahwa adanya pada penurunan asam lemak bebas dengan penambahan antioksidan alami kulit pisang raja yang dapat di lihat berdasarkan rata-rata kadar asam lemak bebas dengan penambahan bubuk kulit pisang raja $1 \% \mathrm{~b} / \mathrm{b}, 2 \% \mathrm{~b} / \mathrm{b}$ dan $3 \% \mathrm{~b} / \mathrm{b}$ yaitu $0,2928 \%, 0,2733 \%$ dan $0,2370 \%$

Disarankan agar adanya penelitian lanjutan terhadap terhadap mutu kualitas minyak jelantah dengan penambahan antioksidan alami kulit pisang raja (Musa sapientum) berdasarkan parameter yang lainnya.

\section{DAFTAR PUSTAKA}

Atun Sri, Arianingrum R, Handayani S, Rudyansah, dan Garson M. 2007. Identifikasi Dan Uji Aktivitas Antioksidan Senyawa Kimia Dari Ekstrak Metanol Kulit Buah Pisang (Musa paradisiaca Linn.). Jurnal Indo. J.Chem., Vol 7(1):8387.Yogyakarta.

Ayucitra, A., Indraswati, N., Mulyandasari, V., Dengi, Y.K., Francisco, G., dan Yudha, A., 2011, Potensi Senyawa Fenolik Bahan Alami sebagai Antioksidan Alami Minyak Goreng Nabati. Jurnal Widya Teknik, 10(1) : 110. Surabaya

Kadarwati Sri. 2007. Regenerasi Minyak Jelantah Dengan Zeolit Alam Sebagai Upaya Peningkatan Kesehatan Masyarakat. Jurnal Kimia Vol 3 no 2. Semarang.

Ketaren S. 2005. Pengantar Teknologi Minyak Dan Lemak Pangan. Penerbit Universitas Indonesia. Jakarta.

Nuramanah Eva.2012. Kajian Aktivitas Antioksidan Kulit Pisang Raja Bulu (Musa Paradiciaca L. Var Sapientum) Dan Produk Olahannya. Repository.Upi.Edu. Universitas Pendidikan Indonesia.

Panangan A T. 2010. Pengaruh Penambahan Bubuk Bawang Merah (allium ascalonicum) Terhadap Bilangan Peroksida dan Kadar Asam Lemak Bebas Minyak Goreng Curah. 10:06-05. Jurnal Penelitian Sains Jurusan Kimia FMIPA, Universitas Sriwijaya. Sumatera Selatan.

Pengaruh Cara Dan Lama Pemeraman Terhadap Kandungan Vitamin C Pada Buah Pisang Raja ( Musa Paradisiaca L). Jurnal FPMIPA. Vol 01. No 02.

Widiandani Tri, Purwanto, Hardjono Suko, Nurbiantoro S. 2009. Pengaruh Penambahan Kulit Pisang Cavendish (Musa Cavendishii) Terhadap Kualitas 
Minyak Kelapa Murni Yang Mengalami Pemanasan Ulang. Majalah Farmasi Airlangga, Vol.7 No.1. Surabaya

Sulieman Mohamed, Abd El-Rahman, Attya El-Makhzangy, dan Mohamed Fawzy Ramadan 2001. Antiradikal Performance and Physicochemicall Characteristics of Vegetable Oils upon Frying of French Fries: A Preliminary Comparative. Electronic Journal of Environmental, Agricultural and Food Chemistry.www.ejeafche.uvigo.es. [22 Februari 2007] 